\title{
Effects of morphine sulfate on the extinction of conditioned escape behavior in the rat ${ }^{\prime 2}$
}

\author{
L. GLENN GOLLINS
}

MENTAL HEALTH RESEARCH INSTITUTE, FORT STEILACOOM, WASHINGTON

\begin{abstract}
This experiment was designed to test the effects of a $7 \mathrm{mg} / \mathrm{kg}$ dose of morphine sulfate on the extinction of a conditioned escape response in rats. Ten male albino rats were conditioned to escape a $30-v$ AC electric shock by running out of a start box, down a 3-ft runway and into a goal box. During extinction trials half the animals received $7 \mathrm{mg} / \mathrm{kg}$ of morphine subcutaneously (s.c.) and half received a subcutaneous (s.c.) injection of physiological saline as a placebo. The morphine group took a significantly greater number of trials to extinguish the escape response. It was concluded that morphine increased the resistance to extinction.
\end{abstract}

\section{Introduction}

The analgesic properties of morphine are well established; however, the sites and mechanisms of action have not been satisfactorily determined. One approach has been to test the effects of morphine on conditioned avoidance and escape behavior. In experiments with dogs (Stephens \& Gantt, 1956) it was found that morphine depressed the motor aspects of the conditioned reflex but did not affect the internal visceral components. Collins (1965), studying the effects of a 7- and a $17-\mathrm{mg} / \mathrm{kg}$ dosage of morphine on the activity-wheel performance of rats, found that while the effects of morphine on spontaneous activity appear to be dependent upon condition of drive, $7 \mathrm{mg} / \mathrm{kg}$ of morphine produced no effect on the activity level of food-deprived subjects (Ss).

Barry \& Miller (1965) report that with rats morphine $(3,6$ and $9 \mathrm{mg} / \mathrm{kg})$ enhanced escape running time and only sightly depressed avoidance running time. Delay time was decreased. Hill, Belleville, \& Wikler (1954), investigating effects of morphine on the conditioned emotional response (CER) in rats, found that morphine, in dosages from 4 to $10 \mathrm{mg} / \mathrm{kg}$, produced proportionate restoration of bar pressing. Belleville (1964), Otis (1964) and Stewart (1962) have demonstrated that drugs. may produce internal changes which can serve as discriminative stimuli. The analgesic properties of morphine could result in these drug-produced stimuli becoming conditioned to the experimental situation. The present study was designed to measure the effect of morphine on the extinction of conditioned escape behavior, so that morphine and pain stimuli are never paired; therefore the drug-produced cues are never associated with analgesia.

\section{Method}

Ten male albino rats approximately four months of age served as Ss. As the animals were maintained on a 24-hr. feeding schedule throughout the experiment, they were always $23 \mathrm{hr}$. hungry at the time of testing. The apparatus consisted of a start box divided into two compartments. The upper compartment contained a hinged floor. When the floor was released by the experimenter, the animal dropped 5 in into the lower compartment, the floor of which was an electric grid. A 3-ft wooden runway connected the start box with the goal box. Latency was recorded by means of electric timers. Timer 1 started when the animal was dropped into the lower starting compartment. Timer 2 started when the animal entered the runway. The difference between the two recordings provided the latency measure. Both timers stopped automatically as the animal entered the goal box. In case an animal remained on the runway for $1 \mathrm{~min}$. the experimenter stopped the timers.

The experiment consisted of three phases: In phase I, the pretreatment activity level was measured during four 50-min. periods separated by one-week intervals. The grid was not charged during this phase. The animals were randomly divided into two groups of five each. One $\mathrm{hr}$. before being placed in the apparatus, one group received a $7 \mathrm{mg} / \mathrm{kg}$ dosage of morphine sulfate subcutaneously (s.c) while the other group received an equal volume of physiological saline s.c. as a placebo. Latency and number of runs made during the 50-min. session were recorded. If an animal remained in the start box for $5 \mathrm{~min}$., it was returned to home cage for the remainder of that session.

During phase II, neither group received an injection prior to being placed in the apparatus. The grid of the start box was charged with 30-v, 60-cycle AC delivered through a Variac. Each animal was given 20 conditioning trials spaced at 1-min. intervals.

During phase III, the shock was turned off and the Ss were run for $1-\mathrm{hr}$. sessions starting $50 \mathrm{~min}$. after injection. The Ss were run at one-week intervals until they reached the extinction criterion of remaining in the start box for $5 \mathrm{~min}$. The morphine group again received $7 \mathrm{mg} / \mathrm{kg}$ of morphine sulfate s.c., and the control group received an equivalent volume of physiological saline s.c. Latency and trials to extinction were recorded.

\section{Results}

Mean latency and number of runs for the phree phases of the experiment are presented in Table $\mathrm{I}$.

The pretreatment activity scores were analyzed for latency and for the number of runs in each session. During phase $I$, the morphine group tended to have a longer latency than the placebo group, but the 
Table 1. Mean Latency (in sec.) and Mean Number of Runs for Morphine and Placebo Groups for the Three Phases of the Experiment.

$\begin{array}{ccr}\begin{array}{c}\text { Phase I } \\ \begin{array}{c}\text { Pretreatment } \\ \text { Activity }\end{array}\end{array} & \begin{array}{c}\text { Phase II } \\ \text { Conditioning }\end{array} & \begin{array}{r}\text { Phase III } \\ \text { Extinction }\end{array} \\ 38.30 & .87 & 5.49 \\ (7.30)^{1} & (20.00) & (214.00) \\ 13.50 & 2.29 & 2.91\end{array}$

Placebo

$$
\text { (1.45) (20.00) }
$$

1. Mean number of runs is shown in parentheses.

difference was not significant $(t=1.43)$. The mean latency for the morphine group was $38.3 \mathrm{sec}$; for the placebo group it was $13.5 \mathrm{sec}$. However, the mean number of runs during phase I was 7.30 for the morphine group and 1.45 for the placebo group. This difference is significant at the .05 level $(t=2.4)$. During the conditioning phase of the experiment (phase II), the animals who had previously received morphine tended to have somewhat shorter latencies than did the placebo animals. The mean for the morphine group was $.87 \mathrm{sec}$. and for the placebo group $2.92 \mathrm{sec}$; however, this difference was not significant at the .05 level $(t=1.69)$. The mean latency for the last 10 trials was .41 sec。for the morphine group and $.37 \mathrm{sec}$. for the control group, indicating that the two groups were conditioned to the same level. For phase III the mean latency for the morphine group was 5.49 and for the placebo group 2.91. This difference is not significant at the .05 level $(t=1.08)$. The mean number of trials to reach the extinction criterion was 214 for the morphine group as opposed to 9 for the placebo group. Since the morphinized animals had a significantly higher activity level during the preconditioning phase of the experiment in terms of number of runs, this difference between the morphinized and placebo animals was covaried out of the extinction data (phase III). The analysis of covariance yielded an F ratio of $20.16(\mathrm{df}=7)$, which is significant beyond the .005 level.

\section{Discussion}

Since the morphine group made a greater number of runs than did the placebo group during both phase I and phase III, it would appear that morphine did not depress the somatic motor response. This is consistent with the finding that $7 \mathrm{mg} / \mathrm{kg}$ of morphine does not depress the activity level of rats (Collins, 1965). The differences in preconditioning activity were covaried out of the extinction data; therefore the greater resistance to extinction shown by the morphine group cannot be accounted for on this basis.

Belleville (1964) and Otis (1964) have demonstrated that responses acquired under a drug condition a re more stable and resistant to extinction in the presence of that drug. 1: we assume that the escape response was partially acquired during phase I, the increased resistance to extinction shown by the morphine group in the present study is consistent with their findings.

The effects of morphine are quite complex, varying with species, dosage and experimental situation. However, a common factor to be considered is that drugproduced stimuli may serve as cues. This factor is of particular relevance in interpreting the effects of morphine of the CER in rats (Hill et al, 1954). In these experiments the restoration of bar pressing during the tone period is taken as evidence of a direct effect of morphine on anxiety. In view of the above-mentioned findings, it is possible that morphine-produced cues come to be associated with decreased painfulness of the electric shock following the tone, and in this indirect way reduce anxiety and restore bar pressing.

\section{Referenees}

Barry, H., III, \& Miller, N. E. Comparison of drug effects on approach, avoidance, and escape motivation. J. comp. physiol. Psychol., 1965, 59, 18-24.

Belleville, R. E. Control of behavior by drug-produced internal stimuli. Psychopharmacologia, 1964, 5, 95-105.

Collins, L. G. Effect of morphine sulfate on spontaneous activity level of the albino rat. Psychol. Rep., 1965, 16, 693-696.

Hill, H. E., Belleville, R. E., \& Wikler, A. Reduction of painconditioned anxiety by analgesic doses of morphine in rats. Proc. Soc. Exp. Biol. Med., 1954, 86, 881-884.

Otis, L. S. Dissociation and recovery of a response learned under the influence of chlorpromazine or saline. Science, 1964, 143, 1347-1348.

Stephens, J. H., \& Gantt, W. H. The differential effect of morphine on cardiac and motor conditional reflexes-schizokinesis. Johns Hopkins Hosp. Bull., 1956, 98, 245-254.

Stewart, Jane. Differential responses based on the physiological consequences of pharmacological agents. Psychopharmacologia, 1962, 3, 132-138,

\section{Notes}

1. This research was conducted at the NIMH Addiction Research Center, Lexington, Kentucky.

2. The author wishes to express his appreciation to the Staff at the NIMH Addiction Research Center and gratefully acknowledge their assistance in conducting this research. 